\title{
MTERFD1 functions as an oncogene
}

\author{
Chaoxiong Zhang ${ }^{1,2, *}$, Ning Wu ${ }^{3, *}$, Fu Gao ${ }^{1, *}$, Jiaqi Han ${ }^{1}$, Yanyong Yang ${ }^{1}$, Chuanfeng \\ Zhou ${ }^{1}$, Weimin Sun ${ }^{4}$, Linfeng Xian ${ }^{1}$, Ying Cheng ${ }^{1}$, Bailong Li ${ }^{1}$, Jianming Cai ${ }^{1}$, Cong Liu ${ }^{1}$ \\ ${ }^{1}$ Department of Radiation Medicine, Faculty of Naval Medicine, Second Military Medical University, Shanghai, 200433, \\ PR China \\ ${ }^{2}$ Institute of Military Medicine, Chengdu Military Region, Chengdu, 610021, China \\ ${ }^{3}$ Department of Respiratory Medicine, Changhai Hospital, Second Military Medical University, Shanghai, 200433, China \\ ${ }^{4}$ Department of Immunology, Second Military Medical University, Shanghai, 200433, People's Republic of China \\ ${ }^{*}$ These authors contributed equally to this work
}

Correspondence to: Jianming Cai, email: caijianming882003@163.com

Cong Liu, email: victorliu20102020@163.com

Keywords: MTERFD1, cancers, prognosis, proliferation, survival

Received: October 02, 2015

Accepted: June 16, 2016

Published: August 09, 2016

\begin{abstract}
MTERFD1, also named MTERF3 (mitochondrial transcription termination factor 3), regulates transcription of the mitochondrial genome. MTERFD1 is a mitochondrial protein that represses mammalian mitochondrial DNA initiation in vivo. In this study, we found that MTERFD1 gene amplification and high expression existed in many different types of cancer. Significantly, increased expression of MTERFD1 gene was correlated with lower overall survival rate in clinical. Overexpression of MTERFD1 gene promoted to tumor cell growth in vivo and in vitro and increased the percentage of cells in S phase. In conclusion, our data firstly indicated the MTERFD1 was an oncogene in many types of cancer.
\end{abstract}

\section{INTRODUCTION}

Recent advances in cancer genomics have led to the paradigm shifts in cancer research. Genomic studies of multiple tumor types have begun to reshape our understanding of cancer genomes and their complexity [1-3]. Emerging genomic data have clearly stablished that each tumor harbors a mixture of cancer-causing genomic aberrations and innocent bystander mutations with no oncogenic potential. Accordingly, distinguishing drivers from passengers in the noisy cancer genome is a crucial step [4].

The Cancer Genome Atlas (TCGA) research network has profiled and analyzed large numbers of human tumors to discover molecular aberrations at the DNA, RNA, protein, and epigenetic levels. The accumulated data provide a major opportunity to develop an integrated model of commonalities, differences and emergent themes across tumor lineages [5]. Data from the TCGA indicate that the human mitochondrial transcription termination factor domain 1 (MTERFD1) was mutated in many types of cancer.

MTERFD1 was involved in the regulation of transcription of the mitochondrial genome. MTERFDI belongs to the MTERF family which consists of four members including MTERF1, MTERF2, MTERF3 and MTERF4 [6]. Previous research showed that MTERFD1 is a mitochondrial protein that interacts with the mitochondrial DNA promoter region and decreases transcription initiation in mammalian mitochondria. This negative regulation is likely important for fine-tuning mitochondria transcription in response to physiological demands [7].

Here, we found the amplification of MTERFD1 gene in many types of cancers. In addition, in vivo and in vitro data indicated that MTERFD1 gene possesses oncogenic properties.

\section{RESULTS}

MTERFD1 amplification occurred in many different types of cancer

Initially, we aligned the human sequences of the four members of the MTERF family of human (Figure S1A), as well as the MTERFD1 sequences of Homo sapiens, Rattus norvegicus and Mus musculus (Figure S1B). Next, we 
found that there was a high amplification rate of MTERFD1 in many types of cancer (Figure 1A). We then compared with the amplification rate of MTERFD1 with those of confirmed oncogenes, including NRAS, HRAS, KRAS [8], TWIST1 [9], SNAI1, SNA2 [10, 11], ABL1 [12] and MDM2 [13]), and found that the amplification frequency of MTERFD1 was higher than these oncogenes (Figure 1B). Moreover, MTERFD1 mRNA level was positively correlated with copy number of MTERFD1 (Figure 1C).

\section{MTERFD1 expression was positively correlated with carcinogenesis, cancer metastasis, estrogen or androgen independence, and cancer immune resistance}

Next, we searched Gene Expression Omnibus (GEO) for data pertaining to the analysis of MTERFD1 expression in different types of cancer. Importantly, we found that a positive correlation exists between MTERFD1 expressions and the cancer clinical stage or subtype. In human colorectal cancer, pancreatic ductal adenocarcinoma, cervical cancer, nasopharynx cancer, rectal cancer, and breast cancer, MTERFD1 expression was higher in tumor tissues than in adjacent normal tissue (Figure 2A). Interestingly, in prostate cancer and melanoma, MTERFD1 mRNA expression was higher in metastatic sites than in the primary tumor. In multistep pancreatic carcinogenesis, MTERFD1 mRNA level was higher in intraductal papillary-mucinous neoplasm (IPMN) than in normal tissue, intraductal papillary-mucinous adenoma (IPMA), and intraductal papillary-mucinous carcinoma (IPMC). In metastatic prostate cancer, the metastatic tumor site tissues showed a higher MTERFD1 mRNA level than the normal, tumor adjacent, and primary tumor site tissues. The breast cancer cell MCF7 showed a higher MTERFD1 expression in tamoxifen resistance cells than in tamoxifen sensitive cells. In prostate cancer, MTERFD1 expression was higher in androgen-dependent than in the androgen independent cells from microdissected primary tumors. In mouse immune resistant lung cancer cell lines, generated by subjecting immune resistant cells to three rounds of in vivo immune selection. We found that MTERFD1 mRNA expression level was higher in immune resistant cell lines than in immune susceptible cell lines. Thus, the above data suggested that MTERFD1 gene played important roles in carcinogenesis, metastasis, estrogen, or androgen related cancers. In addition, data from the mice cell line experiments suggested that MTERFD1 was involved in cancer immune resistance.

\section{Higher MTERFD1 expression in lung cancer, hepatocellular carcinoma, breast cancer, and pancreatic cancer tissues}

We also investigated the MTERFD1 protein expression in various tumor tissues, using MTERFD1 expression in matched adjacent tissues as control. In general, MTERFD1 protein expression was higher in lung cancer tumor tissues, hepatocellular carcinoma, breast cancer, and pancreatic cancer than in normal tissues. In lung cancer, there was only one pair where the adjacent normal tissue showed a higher MTERFD1 protein level. In hepatocellular carcinoma, there were 4 of 55 pairs where adjacent normal tissues showed a higher MTERFD1 protein level. For breast cancer and pancreatic cancer, the ratio of higher MTERFD1 in adjacent normal tissues was 2 of 30 pairs and 5 of 30 pairs, respectively. The representative histology data is shown in Figure 3B. In hepatocellular carcinoma, there were two cancer tissues that showed a lower MTERFD1 protein level (indicated by arrows), and one adjacent normal tissue showed a higher MTERFD1 protein level (indicated by an arrow).

\section{Correlation between MTERFD1 expression and overall survival in different types cancers}

To evaluate the clinical significance of MTERFD1, we investigated whether the alteration of MTERFD1 mRNA expression was associated with overall survival in breast cancer. The Kaplan-Meier survival curves of tumor-free survival and overall survival in cohorts 1 and 2, according to the ratio of MTERFD1 level in each tumor sample compared with its median MTERFD1 level, were shown in Figure 4. In lung cancer, within 10 months, patients with lower MTERFD1 level had a higher survival rate (Figure 4A). The overall survival rate of patients with hepatocellular carcinoma showed a similar trend within 60 months (Figure 4B). More significantly, the overall survival of breast cancer patients during the 200-months follow-up period revealed that low MTERFD1 level favored patient's survival (Figure 4C).

\section{MTERFD1 overexpression promoted tumor growth in vitro}

We also over-expressed MTERFD1 by plasmid transfection. Following transfection, the MTERFD1 expression levels were increased in PANC1, MCF7, HepG2, and A549 cells (Figure 5A). The proliferation analysis with the MTT assay showed that up-regulation of MTERFD1 in these four types of cell lines promoted cell proliferation (Figure 5B). In fact, MTERFD1 overexpression could promote the tumor formation in vitro, especially in PANC1 and MCF7 (Figure 5C). BrdU assay revealed that MTERFD1 overexpression promoted cellular proliferation in PANC1, MCF7, HepG2, and A549 cells (Figure 5D).

\section{MTERFD1 overexpression promoted tumor growth in vivo and reduced the survival rate}

We inoculated MTERFD1-transfected MCF7 cells into nude mice using cells transfected with a blank vector 
as a control (Figure 6A). We found that after six weeks, not only the tumor incidence in MTERFD1-transfected mice was higher than in control, but the size of the formed tumors was larger (Figure 6B). In addition, the tumors derived after inoculation with MTERFD1-transfected MCF7 cells grew faster and were larger than the control in vivo (Figure 6C). The overall survival of tumorinoculated mice was similar to that of cancer patients. In particular, mice that were inoculated with MTERFD1transfected MCF7 cells showed a lower survival rate, whereas all mice in the control survived to the end of the observation period (Figure 6D).

\section{DISCUSSION}

In the study of the oncogenic function of MTERFD1, we found that the amplification of MTERFD1 conferred a selective growth advantage to the cells. This is an important characteristic of mut-driver gene, which is meaningful in tumor molecular therapy. So far, the number of frequently altered mut-driver genes (mountains) is nearing saturation, and a plateau is being reached, because the same mut-driver genes keep being "rediscovered" in different tumor types [14-22].

Approximately 20,000 protein-coding genes have been evaluated in the genome-wide sequencing studies of the 294,881 mutation that have been reported to date. Only 138 mut-driver genes were defined by the 20:20 rules. The 20:20 rules are that, to be classified as an oncogene, $>20 \%$ of the recorded mutation in the gene are at recurrent positions and are missense [1].

Half of the newly found mut-driver genes encode proteins that directly regulate chromatin via the modification of histones or DNA. Examples include the histones HIST1H2B and H3F3A, as well as the proteins DNMT1 and TET1 [1, 23-27]. A previous study has shown that MTERFD1 is a negative regulator of mitochondrial DNA transcription [7], and regulation of mammalian
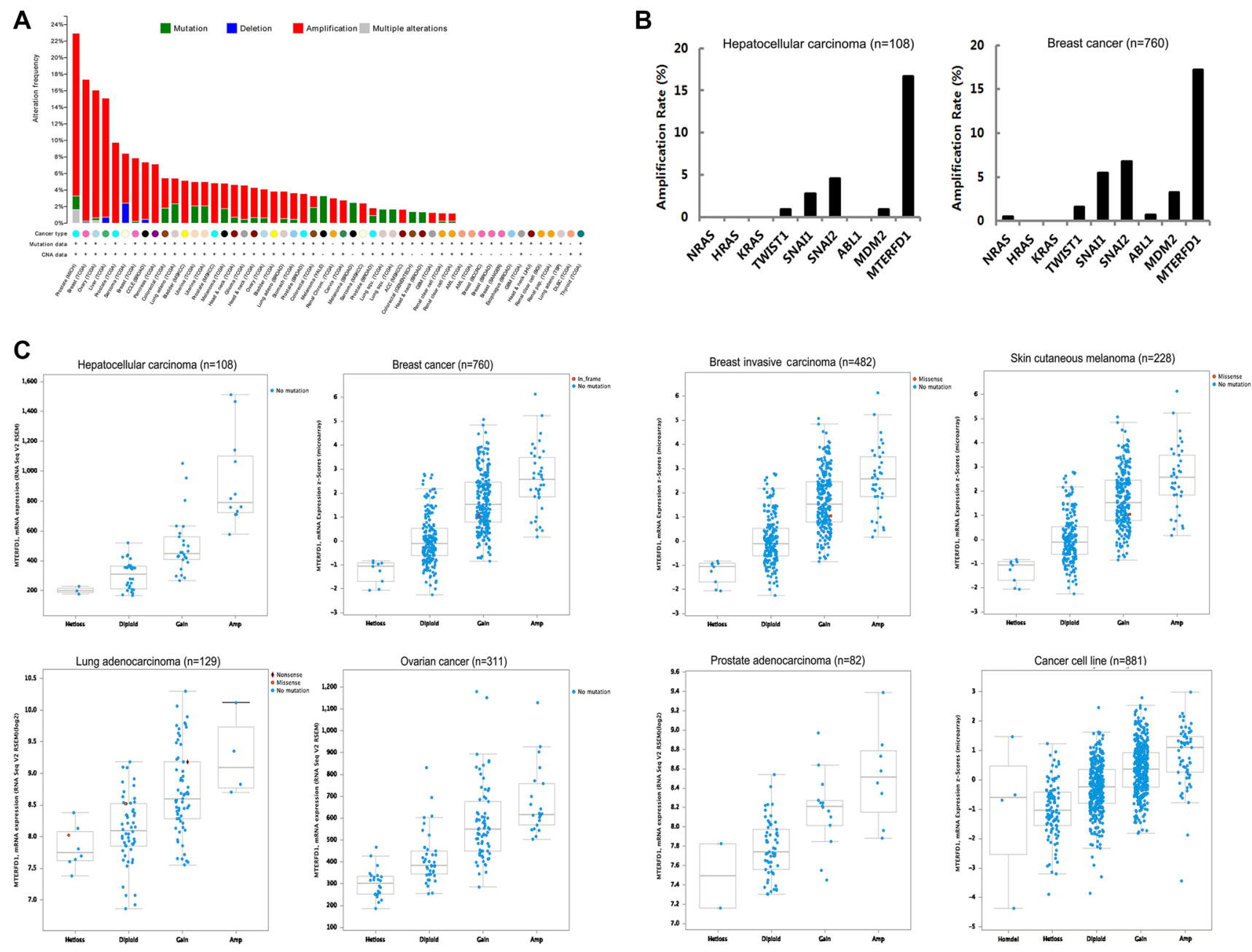

Figure 1: Frequency of alteration of MTERFD1 in various types of cancer. Alteration of $M T E R F D 1$ was visualized using the cBioPortal for Cancer Genomics. Mutation, deletion, amplification, and multiple alterations are shown in different colors. The main alteration of MTERFD1 in different types of cancer is amplification (A). Amplification rate of MTERFD1, NRAS, HRAS, KRAS, TWIST1, SNAI1, SNA2, $A B L 1$ and MDM2 (B). Comparison of MTERFD1 mRNA levels with copy number of MTERFD1 in various types of cancer (C). 
A
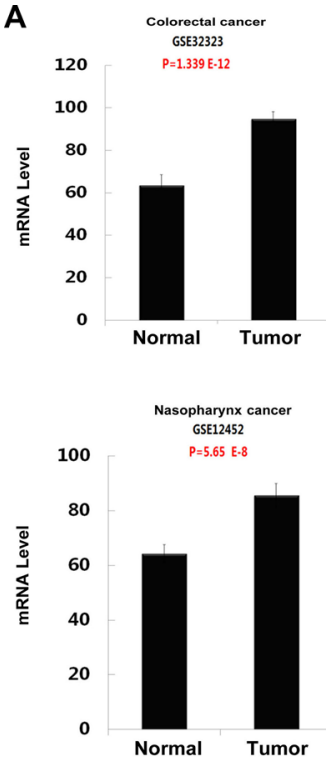

B
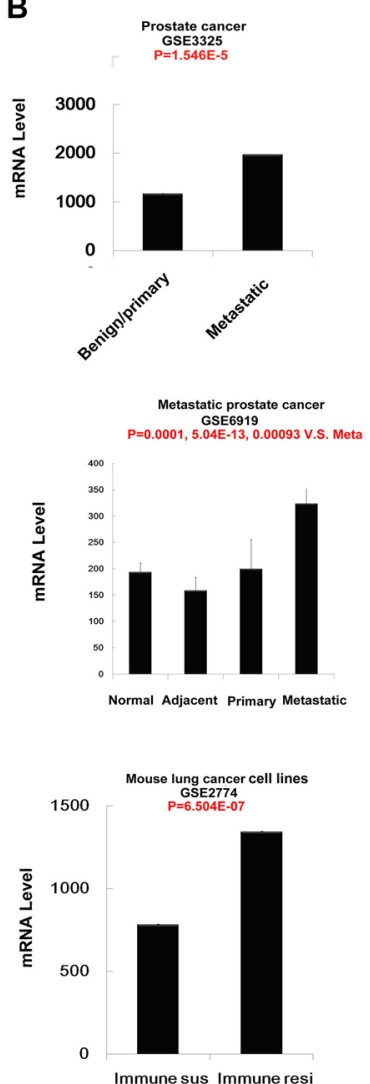
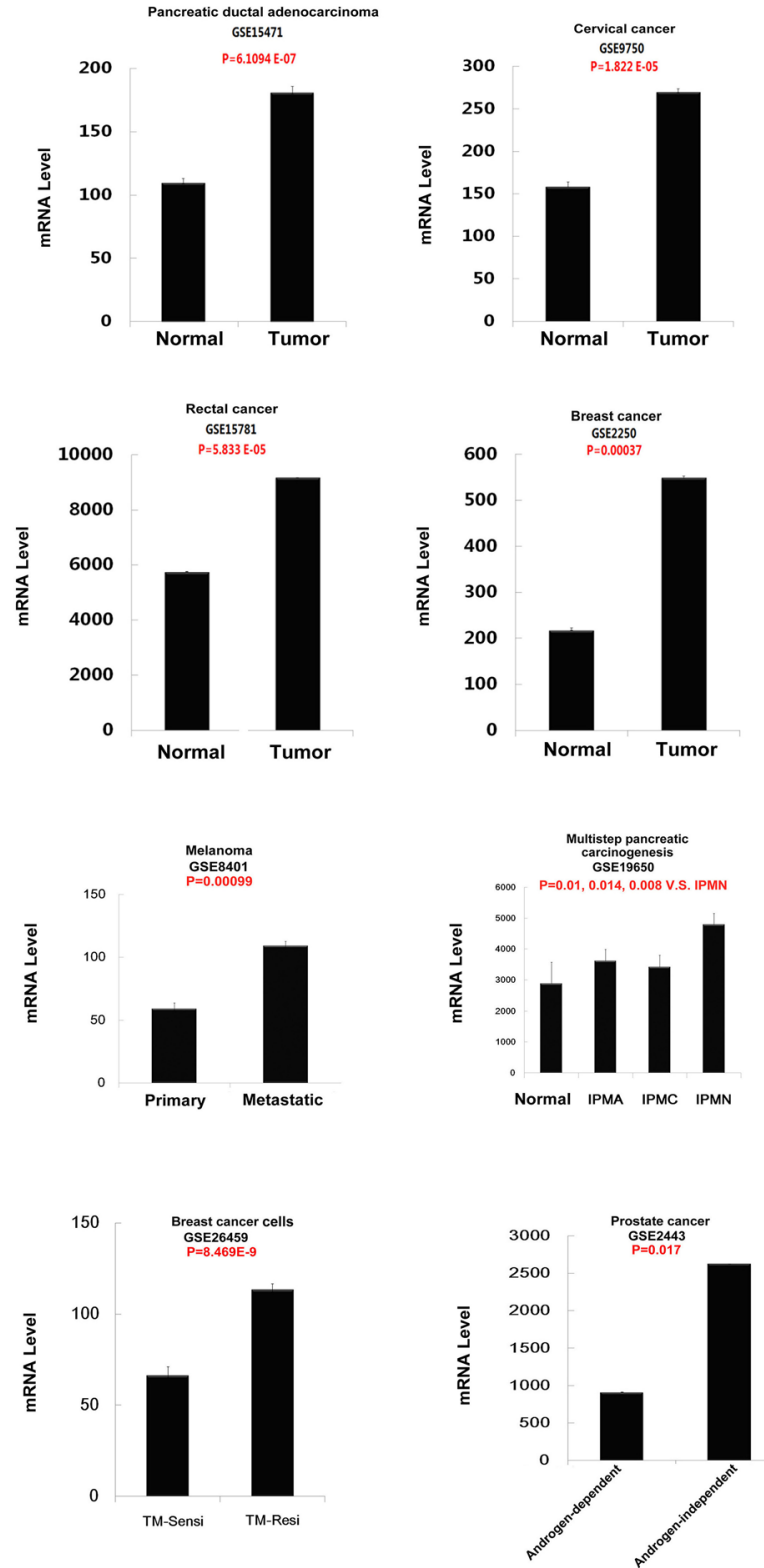

Figure 2: Correlation exists between MTERFD1 expressions and the cancer clinical stage or subtype. MTERFD1 mRNA expression level in tumors was compared with expression in the adjacent normal tissue in colorectal cancer, pancreatic ductal adenocarcinoma, cervical cancer, nasopharynx cancer, rectal cancer, breast cancer, prostate cancer, and melanoma. In multistep pancreatic carcinogenesis, MTERFD1 mRNA expression level in papillary-mucinous neoplasm (PMN), intraductal papillary-mucinous adenoma (IPMA) and intraductal papillary-mucinous carcinoma (IPMC) were compared with expression in normal tissue. In metastatic prostate cancer, the MTERFDI mRNA level in primary tumor site and the metastatic tumor site were compared with the expression in the tumor adjacent tissue. In MCF7 breast cancer cell, the expression of MTERFD 1 in tamoxifen resistance cells and MTERFD1 in tamoxifen sensitive cells were compared. In prostate cancer, expression of MTERFD1 in androgen-dependent cells was higher than androgen-independent microdissected primary tumor cells. In mouse lung cancer cell lines, MTERFD1 mRNA level in immune-resistant cell lines was compared with the expression of MTERFD1 in immune susceptible cell lines. The GSE number was shown in the graphs, data was mean \pm s.e.m. of MTERFD1 expression in different types of cancers $* P<0.05$. 
A<smiles>C#CC#CC#CC#CC#C</smiles>

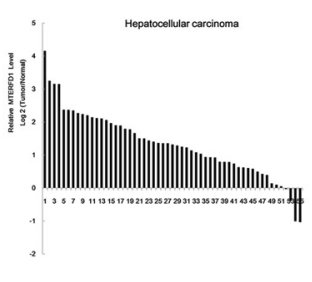<smiles>C#CC#CC#CC#CC#C</smiles>

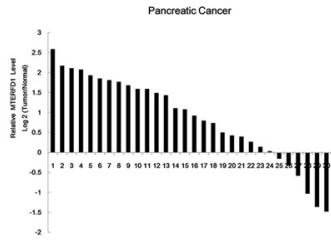

B
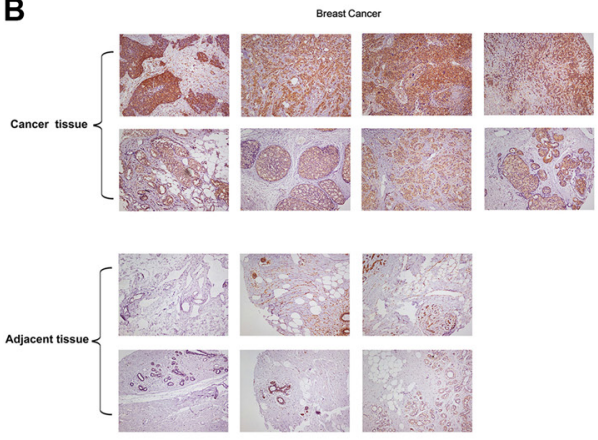

C

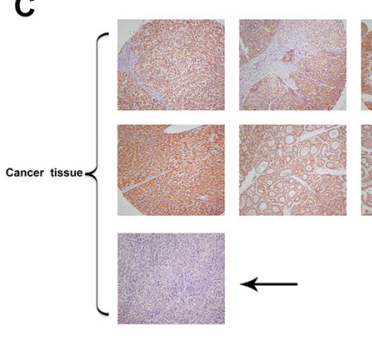

(1)
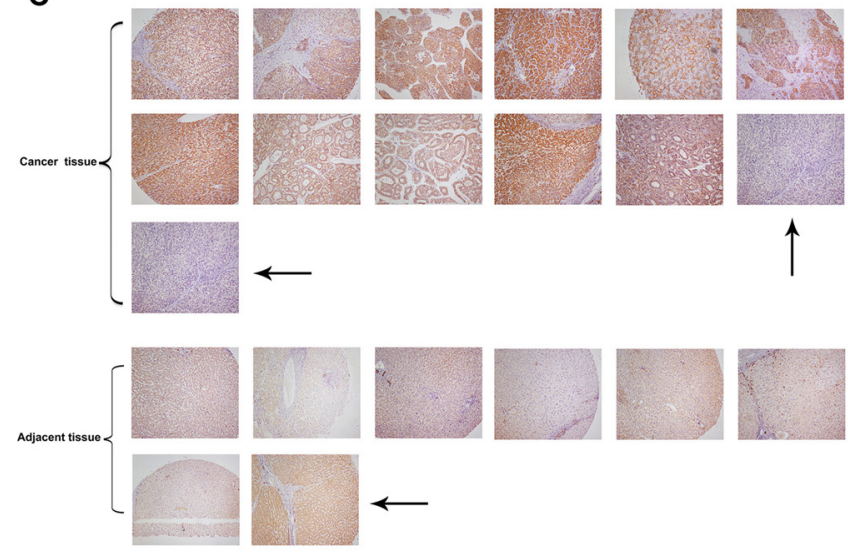

D
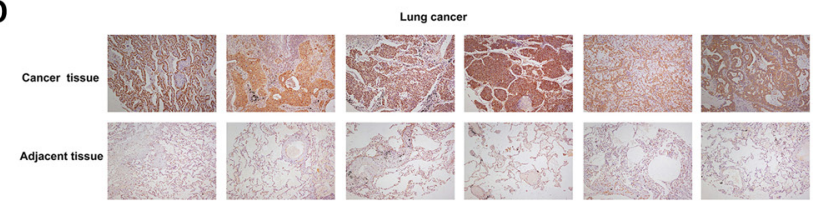

E

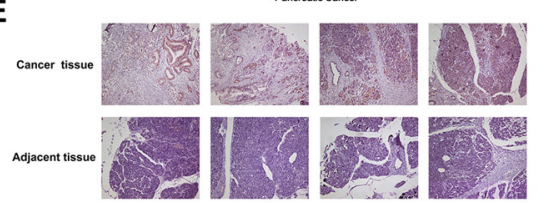

Figure 3: MTERFD1 expression in tumor tissues. The general expression of MTERFD1 in lung tumor tissues, 55 hepatocellular carcinomas, 30 breast cancers, and 30 pancreatic cancer tissues were compared with the matched normal adjacent tissue. The expression value in normal tissue was arbitrarily defined as $100 \%$ (A). Representative Immunohistochemistry analysis of MTERFD1 in breast cancer (B), hepatocellular carcinoma (C), lung cancer (D), pancreatic cancer $(\mathbf{E})$. The arrow in the figures indicated that the cancer tissues have lower MTERFD1 expression, or the adjacent normal tissues have higher MTERFD1 expression.
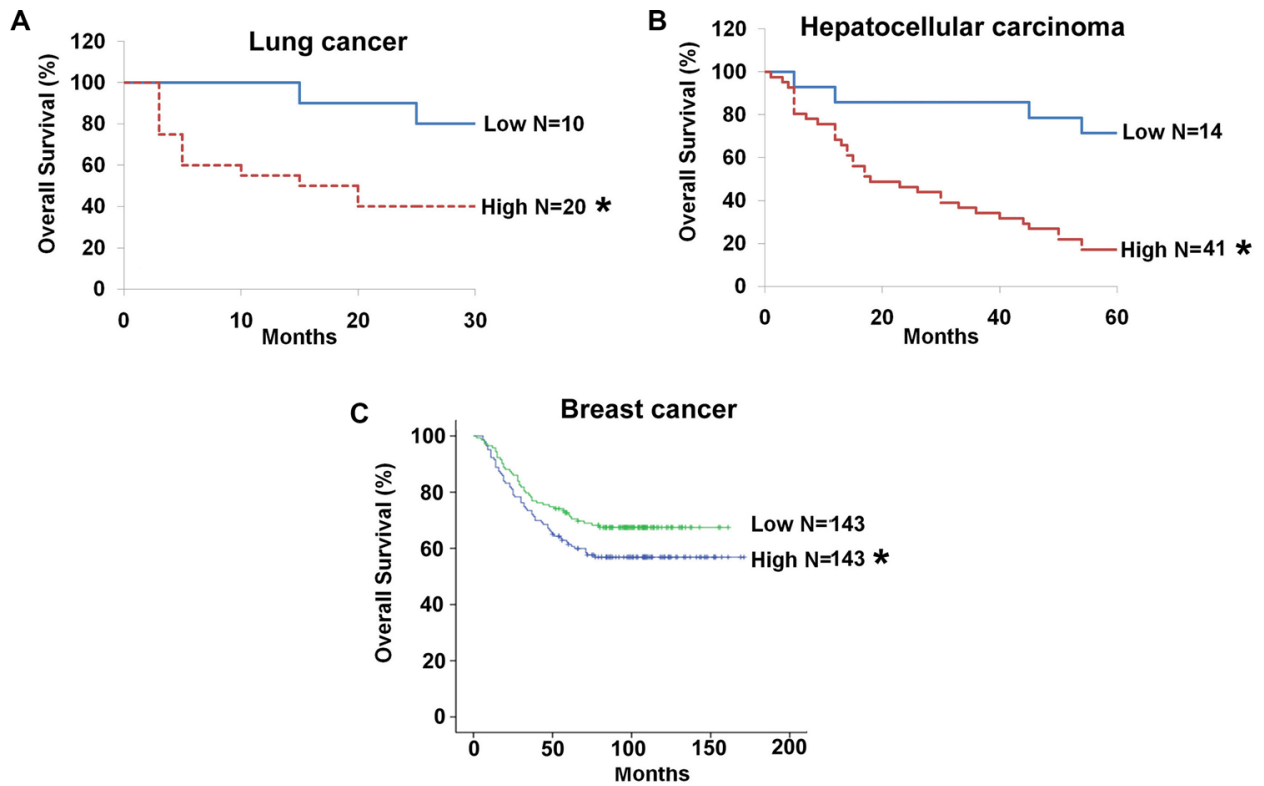

Figure 4: Correlation between MTERFD1 and overall survival in three types of cancer. MTERFD1 expression was divided into low and high expression groups by the corresponding median MTERFD1 level in lung cancers, hepatocellular carcinomas and breast cancers. Kaplan-Meier plots of overall survival in lung cancer patients (A), hepatocellular carcinoma patients (B) and breast cancer patients (C), post-operation according to the expression of MTERFD1 (D). ${ }^{*} P<0.05$. 
A
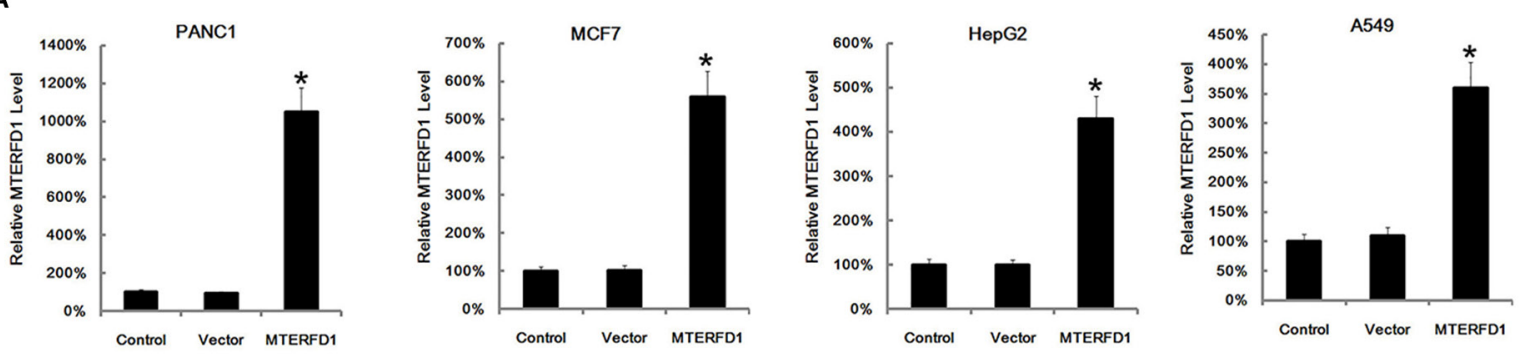

B
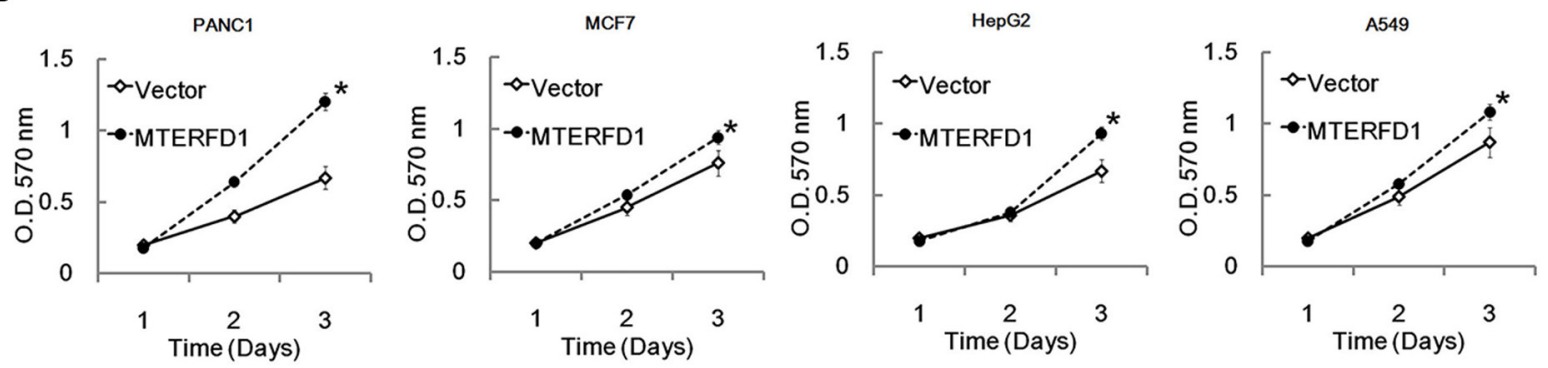

C

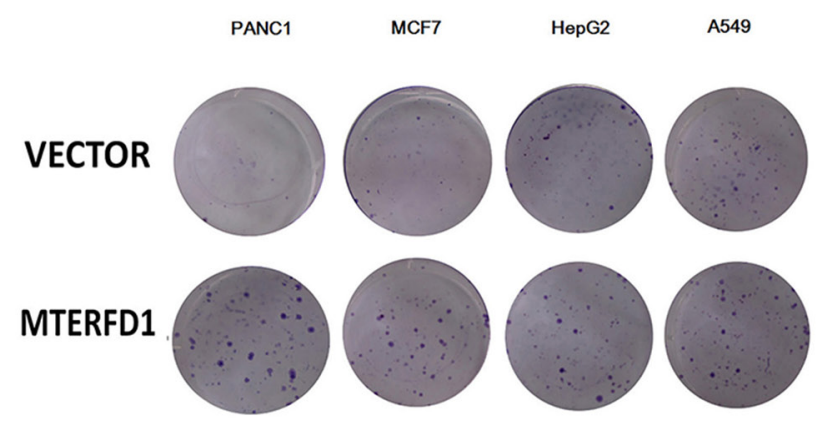

D
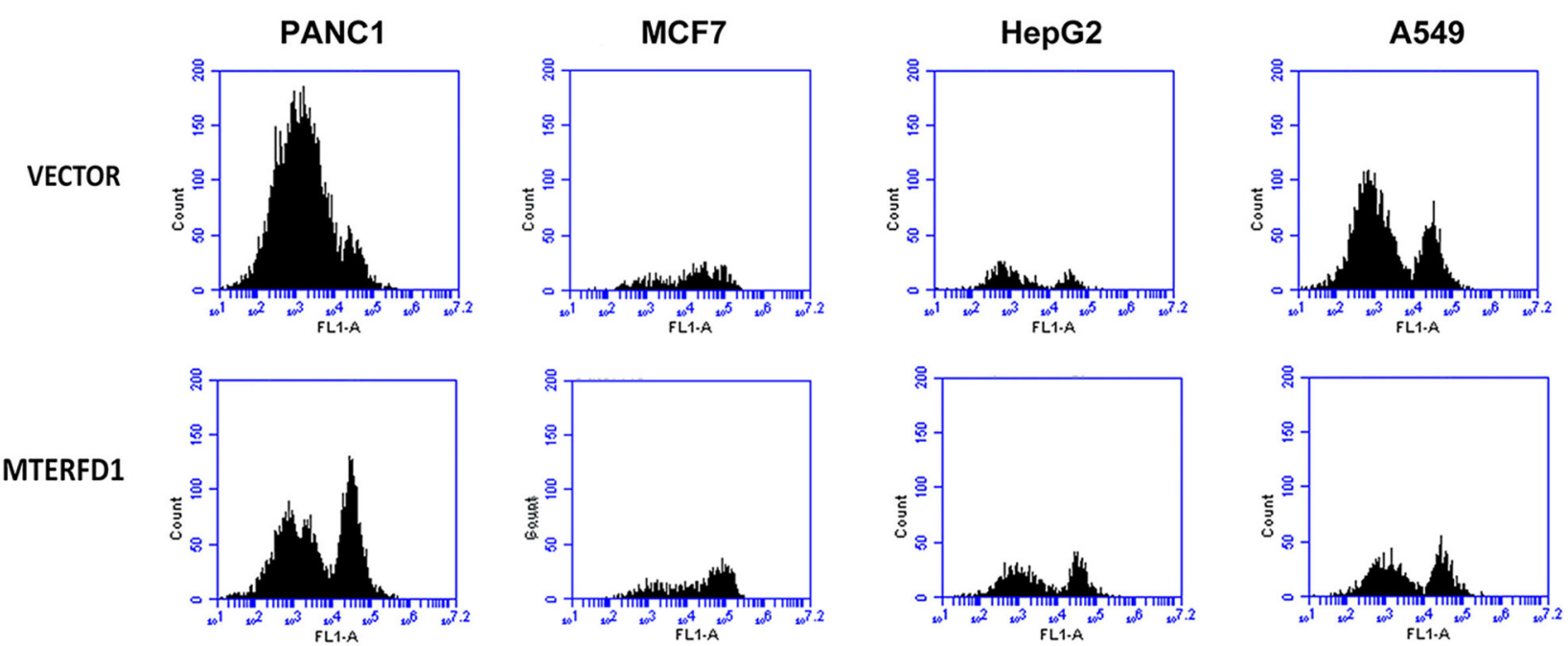

Figure 5: Transfection with an MTERFD1 -overexpressing plasmid promoted tumor growth in vitro. Within 24 hours after transfection with the MTERFD1-overexpressing plasmid, the MTERFD1 mRNA expression was assayed by qRT-PCR in PANC1, MCF7, HepG2 and A549 cell lines (A). Within $24 \mathrm{~h}$ after transfection with the MTERFD1-overexpressing plasmid, the cells growth was assayed by the MTT assay using transfection with an empty plasmid as a control. Data were presented as mean \pm s.e.m. of three independent experiments (B). Within $24 \mathrm{~h}$ after transfection with the MTERFD1-overexpressing plasmid, cell clones in dishes are shown (C). After transfection, the cells were treated with $10 \mu \mathrm{M}$ of BrdU for 1 hour, then were assayed by flow cytometry (D). 
mitochondrial DNA gene expression is critical for altering oxidative phosphorylation to control the physiological capacity in response to physiological demands and disease processes. Accordingly, it seems that MTERFD1 plays its oncogenic function via the regulation of mitochondrial DNA transcription. The precise mechanism however requires further investigation.

Survival analysis highlighted the importance of MTERFD1. Our study revealed a significant correlation between the expression of the MTERFD1 protein and overall survival in different types cancers. $M Y C$ is a classic oncogene. However, the MYC family members are not point-mutated, and recurrently amplified in cancers alongside MTERFD1. For example, in 760 cases of breast invasive carcinoma, there are $180 \mathrm{MYC}$ amplification cases, and 130 MTERFD1 amplification cases.

In conclusion, our study demonstrated the oncogenic function of MTERFD1. Our data indicated that overexpression of MTERFD1 decreased the survival by promoting tumor cells growth. Our study may provide a potential target for therapy.
A

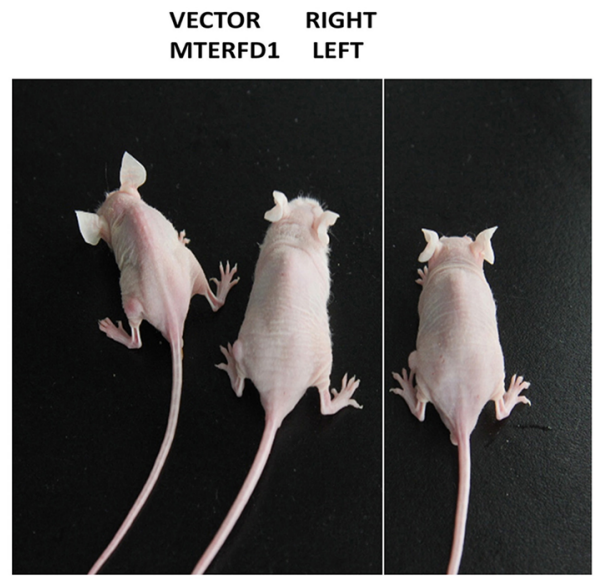

C

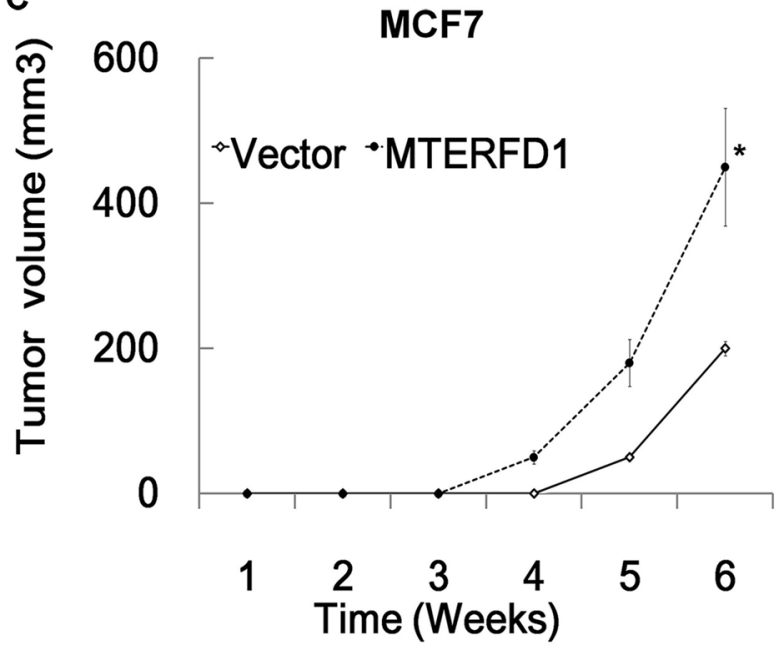

B
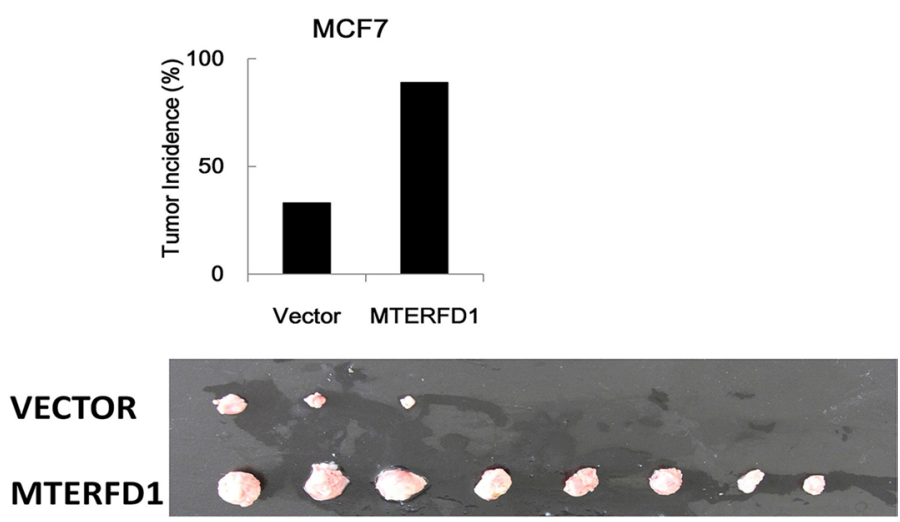

D

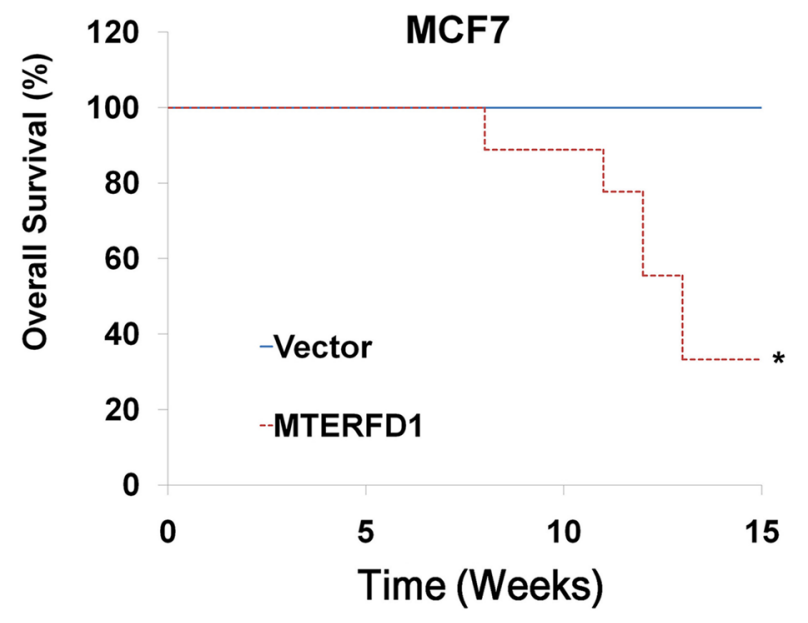

Figure 6: MTERFD1 overexpression promoted tumor growth in vivo and reduced the survival rate. Nude mice were inoculated with cells overexpressing MTERFD1 (MCF7 transfected with plasmid). The subcutaneous tumors formed after 6 weeks are shown (A). Ten nude mice were subcutaneously inoculated with MCF7 cells transfected with the MTERFD1-overexpressing plasmid. Ten nude mice, used as control, were subcutaneously inoculated with MCF7 cells transfected with an empty plasmid. The tumor incidence was calculated, and the subcutaneous tumors were isolated and measured (B). After the inoculation, the tumor volumes were measured every week. Data were presented as mean \pm s.d. of the measurement of 10 mice $(\mathbf{C})$. Kaplan-Meier plot of overall survival post-inoculation according to the expression of MTERFD1 (D). $* P<0.05$. 


\section{MATERIALS AND METHODS}

\section{Gene and protein sequence alignment}

MTERFD1 gene and protein sequences were aligned with those of the other three members of the MTERF family by using COBALT [28]. Additionally, MTERFDI of different species (Homo sapiens, Rattus norvegicus and Mus musculus) were also aligned using the same approach.

\section{Gene alteration frequency analysis in cancer}

The data of MTERFD1 alteration frequency and mRNA expression level analyses were queried from TCGA via the cBioportal for Cancer Genomics (http:// www.cbioportal.org/public-portal/index.do) $[29,30]$.

\section{MTERFD1 mRNA expression level analysis}

The data of MTERFD1 mRNA expression in various types of cancer were queried from Gene Expression Omnibus.

\section{Tissue microarray analysis and survival analysis}

Lung cancer, hepatocellular carcinoma, breast cancer, and pancreatic cancer tissue microarrays were purchased from and analyzed by SHANGHAI OUTDO BIOTECH CO.,LTD (Shanghai, China). These tissues were obtained postoperatively from Changhai Hospital, Second Military Medical University (Shanghai, China). All patients gave signed, informed consent for their tissues to be used for scientific research. Ethical approval for the study was obtained from Changhai Hospital, Second Military Medical University. All diagnoses were based on pathological and/or cytological evidence. The histological features of the specimens were evaluated by senior pathologists according to the World Health Organization classification criteria. Tissues were obtained before chemotherapy and radiotherapy and were immediately frozen and stored, at the SHANGHAI OUTDO BIOTECH CO., LTD, at $-80^{\circ} \mathrm{C}$ prior to qRTPCR analysis. Corresponded patients were followed-up for the indicated number of years and all clinical data were electronically recorded.

\section{Cell culture}

Human pancreatic carcinoma cell line (PANC1), human breast cancer cell lines (MCF7), human hepatocarcinoma cell lines (HepG2) and human non-small cell lung cancer (A549) cell lines were purchased from ATCC (Manassas, VA, USA) and cultured in DMEM or 1640 medium cultured in DMEM medium (Hyclone, South Logan, UT, USA) supplemented with $10 \%$ fetal bovine serum (Hyclone), $2 \mathrm{mM}$ L-glutamine and $100 \mu \mathrm{g} / \mathrm{mL}$ penicillin/streptomycin (Bio Light, Shanghai, China) as described in our previous studies [31].

\section{Plasmid transfection}

MTERFD1 overexpression plasmid (pcDNA3.1MTERFD1) was designed, constructed and confirmed by the SHANGHAI SHENGONG company (Shanghai, China). Plasmids were transfected into cells $\left(6 \times 10^{4}\right.$ cells per well) using Lipofectamine 2000 (Invitrogen, Carlsbad, CA, USA) according to the manufacturer's instructions. Cells were collected after $48 \mathrm{~h}$ for confirmation and further analysis.

\section{Mice and treatment}

Nude mice (6 weeks) were obtained from the Animal center of the Chinese Academy of Science (Shanghai, China), and maintained in the nude mice care center of the Second Military Medical University. MCF7 cells were subcutaneously inoculated into nude mice at the density of $1 \times 10^{7} \mathrm{cell} / \mathrm{mL}$, in a $500 \mathrm{~mL}$ volume. After the MCF7 cells inoculation, mice were monitored and the tumor volumes were measured every week. During the 15-weeks followup period, the survival status of nude mice was recorded.

\section{RNA extraction and real time q-PCR analysis}

RNA was extracted with the Trizol reagent (Invitrogen, Carlsbad, CA, USA) following the manufacturer's protocol. The cDNA synthesis and realtime qPCR were subsequently performed using the Qiagen system as described in detail in our previous studies [31]. Real-time quantitative PCR analysis was performed using standard protocols on an Applied Biosystem's 7500 Fast Real-Time PCR System (ABI, Foster City, CA, USA).

\section{Cell growth assay}

For cell growth assay, 500 cells per well were seeded in triplicate in a 96-well plate with complete growth medium. Cells were counted over 5 days using the MTT assay (Promega, Fitchburg, WI, USA) as previously described [31-34].

\section{Edu cell proliferation assay}

The cell proliferation were assayed by Edu (5-ethynyl-2'-dexoxyuridine) Flow Assay Kits (Promega, Fitchburg, WI, USA) Edu is a nucleoside analog to thymidine and is incorporated into DNA during DNA synthesis. Flow Cytometry assay was performed by using CellQuest Software (Becton Dickinson, Franklin Lakes, NJ, USA) as described previously [35]. 


\section{Statistical analysis}

Data, from at least three independent experiments, are presented as the mean \pm s.e.m. The difference between groups was analyzed using a two-tailed Student's $t$ test when only two groups were compared. The difference between groups were analyzed using ANOVA when three or more groups were compared. Survival was evaluated by Kaplan-Meier analysis. Statistical analyses were performed using SPSS software version 17.0 (IBM, Armonk, NHY, USA). $P<0.05$ was considered significantly different.

\section{ACKNOWLEDGMENTS AND FUNDING}

This work was supported by the grant from National Natural Science Foundation of China (No. 31170827, No. 81402630, NO. 81201850 and NO. 81573092).

\section{CONFLICTS OF INTEREST}

The authors have declared that no competing interests exist.

\section{REFERENCES}

1. Vogelstein B, Papadopoulos N, Velculescu VE, Zhou S, Diaz LA, Jr, Kinzler KW. Cancer genome landscapes. Science. 2013; 339:1546-1558.

2. Hudson TJ, Anderson W, Artez A, Barker AD, Bell C, Bernabe RR, Bhan MK, Calvo F, Eerola I, Gerhard DS, Guttmacher A, Guyer M, Hemsley FM, et al. International network of cancer genome projects. Nature. 2010; 464:993-998.

3. Ciriello G, Miller ML, Aksoy BA, Senbabaoglu Y, Schultz N, Sander C. Emerging landscape of oncogenic signatures across human cancers. Nat Genet. 2013; 45:1127-1133.

4. Chin L, Andersen JN, Futreal PA. Cancer genomics: from discovery science to personalized medicine. Nat Med. 2011; 17:297-303.

5. Cancer Genome Atlas Research N, Weinstein JN, Collisson EA, Mills GB, Shaw KR, Ozenberger BA, Ellrott K, Shmulevich I, Sander C, Stuart JM. The Cancer Genome Atlas Pan-Cancer analysis project. Nature genetics. 2013; 45:1113-1120.

6. Linder T, Park CB, Asin-Cayuela J, Pellegrini M, Larsson NG, Falkenberg M, Samuelsson T, Gustafsson CM. A family of putative transcription termination factors shared amongst metazoans and plants. Curr Genet. 2005; 48:265-269.

7. Park CB, Asin-Cayuela J, Camara Y, Shi Y, Pellegrini M, Gaspari M, Wibom R, Hultenby K, Erdjument-Bromage H, Tempst P, Falkenberg M, Gustafsson CM, Larsson NG. MTERF3 is a negative regulator of mammalian mtDNA transcription. Cell. 2007; 130:273-285.
8. Parikh C, Subrahmanyam R, Ren R. Oncogenic NRAS, KRAS, and HRAS exhibit different leukemogenic potentials in mice. Cancer Res. 2007; 67:7139-7146.

9. Maestro R, Dei Tos AP, Hamamori Y, Krasnokutsky S, Sartorelli V, Kedes L, Doglioni C, Beach DH, Hannon GJ. Twist is a potential oncogene that inhibits apoptosis. Genes Dev. 1999; 13:2207-2217.

10. Franci C, Takkunen M, Dave N, Alameda F, Gomez S, Rodriguez R, Escriva M, Montserrat-Sentis B, Baro T, Garrido M, Bonilla F, Virtanen I, Garcia de Herreros A. Expression of Snail protein in tumor-stroma interface. Oncogene. 2006; 25:5134-5144.

11. Wu K, Bonavida B. The activated NF-kappaB-Snail-RKIP circuitry in cancer regulates both the metastatic cascade and resistance to apoptosis by cytotoxic drugs. Crit Rev Immunol. 2009; 29:241-254.

12. Gorre ME, Mohammed M, Ellwood K, Hsu N, Paquette R, Rao PN, Sawyers CL. Clinical resistance to STI-571 cancer therapy caused by BCR-ABL gene mutation or amplification. Science. 2001; 293:876-880.

13. Chene P. Inhibiting the p53-MDM2 interaction: an important target for cancer therapy. Nat Rev Cancer. 2003; 3:102-109.

14. Parsons DW, Li M, Zhang X, Jones S, Leary RJ, Lin JC, Boca SM, Carter H, Samayoa J, Bettegowda C, Gallia GL, Jallo GI, Binder ZA, et al. The genetic landscape of the childhood cancer medulloblastoma. Science. 2011; 331:435-439.

15. Pasqualucci L, Trifonov V, Fabbri G, Ma J, Rossi D, Chiarenza A, Wells VA, Grunn A, Messina M, Elliot O, Chan J, Bhagat G, Chadburn A, et al. Analysis of the coding genome of diffuse large B-cell lymphoma. Nat Genet. 2011; 43:830-837.

16. Morin RD, Mendez-Lago M, Mungall AJ, Goya R, Mungall KL, Corbett RD, Johnson NA, Severson TM, Chiu R, Field M, Jackman S, Krzywinski M, Scott DW, et al. Frequent mutation of histone-modifying genes in nonHodgkin lymphoma. Nature. 2011; 476:298-303.

17. Grasso CS, Wu YM, Robinson DR, Cao X, Dhanasekaran SM, Khan AP, Quist MJ, Jing X, Lonigro RJ, Brenner JC, Asangani IA, Ateeq B, Chun SY, et al. The mutational landscape of lethal castration-resistant prostate cancer. Nature. 2012; 487:239-243.

18. Ellis MJ, Ding L, Shen D, Luo J, Suman VJ, Wallis JW, Van Tine BA, Hoog J, Goiffon RJ, Goldstein TC, Ng S, Lin L, Crowder R, et al. Whole-genome analysis informs breast cancer response to aromatase inhibition. Nature. 2012; 486:353-360.

19. Wiegand KC, Shah SP, Al-Agha OM, Zhao Y, Tse K, Zeng T, Senz J, McConechy MK, Anglesio MS, Kalloger SE, Yang W, Heravi-Moussavi A, Giuliany R, et al. ARID1A mutations in endometriosis-associated ovarian carcinomas. N Engl J Med. 2010; 363:1532-1543.

20. Jones S, Wang TL, Shih Ie M, Mao TL, Nakayama K, Roden R, Glas R, Slamon D, Diaz LA Jr, Vogelstein B, 
Kinzler KW, Velculescu VE, Papadopoulos N. Frequent mutations of chromatin remodeling gene ARID1A in ovarian clear cell carcinoma. Science. 2010; 330:228-231.

21. Wang K, Kan J, Yuen ST, Shi ST, Chu KM, Law S, Chan TL, Kan Z, Chan AS, Tsui WY, Lee SP, Ho SL, Chan $\mathrm{AK}$, et al. Exome sequencing identifies frequent mutation of ARID1A in molecular subtypes of gastric cancer. Nat Genet. 2011; 43:1219-1223.

22. Zhang Z. Genomic landscape of liver cancer. Nat Genet. 2012; 44:1075-1077.

23. Delhommeau F, Dupont S, Della Valle V, James C, Trannoy S, Masse A, Kosmider O, Le Couedic JP, Robert F, Alberdi A, Lecluse Y, Plo I, Dreyfus FJ, et al. Mutation in TET2 in myeloid cancers. N Engl J Med. 2009; 360:2289-2301.

24. Schwartzentruber J, Korshunov A, Liu XY, Jones DT, Pfaff E, Jacob K, Sturm D, Fontebasso AM, Quang DA, Tonjes M, Hovestadt V, Albrecht S, Kool M, et al. Driver mutations in histone $\mathrm{H} 3.3$ and chromatin remodelling genes in paediatric glioblastoma. Nature. 2012; 482:226-231.

25. Wu G, Broniscer A, McEachron TA, Lu C, Paugh BS, Becksfort J, Qu C, Ding L, Huether R, Parker M, Zhang J, Gajjar A, Dyer MA, et al. Somatic histone H3 alterations in pediatric diffuse intrinsic pontine gliomas and nonbrainstem glioblastomas. Nat Genet. 2012; 44:251-253.

26. Ley TJ, Ding L, Walter MJ, McLellan MD, Lamprecht T, Larson DE, Kandoth C, Payton JE, Baty J, Welch J, Harris CC, Lichti CF, Townsend RR, et al. DNMT3A mutations in acute myeloid leukemia. N Engl J Med. 2010; 363:2424-2433.

27. Dalgliesh GL, Furge K, Greenman C, Chen L, Bignell G, Butler A, Davies H, Edkins S, Hardy C, Latimer C, Teague J, Andrews J, Barthorpe S, et al. Systematic sequencing of renal carcinoma reveals inactivation of histone modifying genes. Nature. 2010; 463:360-363.

28. Papadopoulos JS, Agarwala R. COBALT: constraintbased alignment tool for multiple protein sequences. Bioinformatics. 2007; 23:1073-1079.
29. Cerami E, Gao J, Dogrusoz U, Gross BE, Sumer SO, Aksoy BA, Jacobsen A, Byrne CJ, Heuer ML, Larsson E, Antipin Y, Reva B, Goldberg AP, et al. The cBio cancer genomics portal: an open platform for exploring multidimensional cancer genomics data. Cancer Discov. 2012; 2:401-404.

30. Gao J, Aksoy BA, Dogrusoz U, Dresdner G, Gross B, Sumer SO, Sun Y, Jacobsen A, Sinha R, Larsson E, Cerami E, Sander C, Schultz N. Integrative analysis of complex cancer genomics and clinical profiles using the cBioPortal. Sci Signal. 2013; 6:pl1.

31. Wu N, Liu C, Bai C, Han YP, Cho WC, Li Q. OverExpression of Deubiquitinating Enzyme USP14 in Lung Adenocarcinoma Promotes Proliferation through the Accumulation of beta-Catenin. Int J Mol Sci. 2013; 14:10749-10760.

32. Liu C, Li B, Cheng Y, Lin J, Hao J, Zhang S, Mitchel RE, Sun D, Ni J, Zhao L, Gao F, Cai J. MiR-21 plays an important role in radiation induced carcinogenesis in $\mathrm{BALB} / \mathrm{c}$ mice by directly targeting the tumor suppressor gene Big-h3. Int J Biol Sci. 2011; 7:347-363.

33. Liu C, Gao F, Li B, Mitchel RE, Liu X, Lin J, Zhao L, Cai J. TLR4 knockout protects mice from radiation-induced thymic lymphoma by downregulation of IL6 and miR-21. Leukemia. 2011; 25:1516-1519.

34. Liu C, Zhou C, Gao F, Cai S, Zhang C, Zhao L, Zhao F, Cao F, Lin J, Yang Y, Ni J, Jia J, Wu W, et al. MiR-34a in age and tissue related radio-sensitivity and serum miR-34a as a novel indicator of radiation injury. Int J Biol Sci. 2011; 7:221-233.

35. Johnnidis JB, Harris MH, Wheeler RT, Stehling-Sun S, Lam MH, Kirak O, Brummelkamp TR, Fleming MD, Camargo FD. Regulation of progenitor cell proliferation and granulocyte function by microRNA-223. Nature. 2008; 451:1125-1129. 